\title{
Affects, Interfaces, Events
}

BODIL MARIE STAVNING THOMSEN, JETTE KOFOED \& JONAS FRITSCH

This book addresses how the proliferation of digital and interfacial technologies produces an intensified distribution of affect in most aspects of our daily lives. Interfacial encounters imply a folding between "being in the body and representing/mapping the body from the outside" (Munster 2006,142 ). Our key concern is to analyze the often-complex interfacial entanglements between our online and our offline being-in-the-world, since the distribution of affect modulates our very existential conditions. The individual chapters of the book investigate, in numerous ways, how affective interfacial events - on a micro and macro-level-are reinforced by or challenged by these conditions. The major concerns that we consider are: what happens in specific interfacial encounters, how interfaces modulate, how tonalities are brought forth or can change environments, how attunements happen, and how interfacial spreadings operate on affective, aesthetic, and political levels of exchange. These investigations are carried out from a transdisciplinary starting point, bringing into creative resonance a multiplicity of concepts, methods, and empirical examples throughout the overall framing of the book.

The individual chapters of Affects, Interfaces, Events relate to interfacial events produced and received as (real-time) encounters within global electronic and digital media networks, but the chapters also attend to a wider consideration of events including the circuits of analogue and electronic media. The examples offered within the chapters include actual interface designs, artworks reflecting on or an-archiving the operations of interfaces, interfacial city planning as well as media ecologies that stress or intensify interfacial encounters. The enhancing of joyful encounters as well as tiresome ones are explored in detail. In this sense, the term 'interface' 
should neither be read as a technical term covering operations and functionalities (e.g., adhering to AI, to big data, or to surveillance capitalism); neither should it include all kinds of exchange taking place between more entities or conditions.

The critical ambition of this book is to dive into the oscillations of the three key terms - affects, interfaces, events - and to decipher the vibrations, modulations, and shifts occurring in the "signaletic material" (Deleuze 1989; Thomsen 2012) of data (algorithmic or not) that forms our contemporary condition. In asking the question, 'What do interfaces do?' it is the intention of this book to unpack the affective implications of how interfacial encounters take part in events.

In other words, the overall contribution of the book extends the wellknown question, 'What can a body do?' in Spinoza and Deleuze (Spinoza 1677; Deleuze 1988; Gregg \& Seigworth 2010) to the contemporary question of 'what can an interface do?' In this sense the interface is, in this volume, the prism through which affective reactions and affective encounters are registered, studied, and brought into wider cultural, societal, and political contexts. Some interfacial encounters can certainly bring sad passions in the forms of hatred, aversion, mockery, fear, and despair that are all too often re-circulated in media; other encounters bring active joys, inspiring to a power to act and change perceptions and life conditions. Importantly, however, even though such passions are colored by different kinds of technologies, they are not predetermined by them. As an example, Virtual Reality (VR) technologies are simultaneously used for warfare training as well as post-war trauma therapy, this shows how the (same) digital technologies/materials can be used to serve different, even directly opposed, aims. This raises important ethical questions as to how our current techno-ecologies could be reimagined.

Interfaces have for a long time been part of all kinds of communication and 'operations' via video cameras, screenings, data-processing etc. Today the relational exchanges in interfacial real time encounters (for example in social media) have a folding and reflective capacity that influences the communication just as much as the actual messages sent or received. Whereas most theories of communication explain the exchanges taking place between sender and receiver as a relation between two parts, the concept of interfacial folding adds a layer onto communication of recording/sending/data-assemblage in real-time. Algorithmic data feedback procedures appear to have replaced a more representational and cause-ef- 
fect based production of 'meaning.' Classical news media have primarily understood this condition as the 'downfall' of critical engagement. This downfall is seen to invite an open platform for 'fake news.' However, things are more complex. The hashtag \#MeToo, for example, demonstrates how fast an affective interface event can make an impact and change tonalities. Affective interface events can twist, turn, and draw unforeseen lines of affinity and crowding - and make change possible. Taking into account the folding intensity of interfaces is a complex and troublesome task that is not often covered by theoretical writings on interfaces. The trouble with considering interfacial foldings might be even less convenient to a range of current interfacial practices where ideals such as smoothness, transparency, and seamlessness still persist.

The chapters within this book aim to expand the understanding of interfacial encounters and to heighten awareness of the relational, folding capacity of interfaces. Instead of studying exchanges taking place between two parts-so-called subjects and objects-we propose to shift focus to the highly intensive middling of interfaces. Thus, the folding intensification or triangulation of interfaces consists in, 1) activating keyboard, keypad, camera or button 2) in perceiving the screening and screened material and, 3) in exploring the feedback data. The first two operations might easily take place in analogue writing or drawing for example, while the third operation implies an awareness of and access to how data is coded, shared, and archived. This operation might rather be referred to as signaletic material since its significance is motion and algorithmic modulation. Nevertheless, and even though this third operation of the interface does not necessarily involve or include a human agent, sensing it takes part in all interfacial encounters. Affect is felt as arising within interfacial encounters that entangle the mental, the social, and the environmental (cf. Guattari 1989/2000) just as much as off-line encounters, since affect can be produced and sensed independently-free of meaning and sense (as attributed to narration or sign systems referring to analogue forms of communication).

The global covid-19 pandemic has run parallel to the editorial work with the book. Its impact can in some ways help explain what we refer to as events. The pandemic has certainly put an end to global exchanges that have international travels and overnight hotel stays as key components. Instead, we have seen a rapid increase in remote interfacial encounters that have been crucial to upholding all kinds of relationalities: meetings, 
teaching, and counselling. This has also resulted in 'zoom fatigue' and exhaustion. We might conceptualize this as the 'revenge of the screen' in a time of social distancing, both facilitating contact but also making felt the loss of physical touch in our everyday lives at a time when we have been asked to "stand together apart."

In a growing number of countries, mobile apps have become key to registering the spread of the virus - for some this is seen as a furthering of biopolitical governmentality and neoliberal capture of our most intimate data, with ensuing questions about ethics and privacy; for others the apps are seen as a necessary technological intervention to help cope with the pandemic. In the case of the steep rise in remote meetings, a related consequence has also been a positive impact on the environment due to a reduction in $\mathrm{CO} 2$ emissions. And we have seen examples of how the lockdowns can create the necessary time and space to imagine alternatives to neo-liberal capitalistic agendas and hectic lives. However, the pandemic and the economic downturn has also set a new framework for interfacial comparison of inequality on a global scale. Huge variations between different nations' conditions of work and housing, as well as access to healthcare systems, became exposed on a global scale in relation to (the lack of) governmental support. Especially the life conditions of migrants and people with precarious jobs were measurable in the death rates within welfare states. So, even though perceptible changes have been the pandemic's consequences for most people, the inequal conditions of staying healthy is spelled out, and the impact of the lack of basic health conditions in many generations of marginalized or vulnerable sections of the population worldwide is a major wake-up call for those that deny social inequality.

One decisive moment re-ignited the Black Lives Matter movement, namely the death of George Floyd at the hands of the police. His last words "I can't breathe!" were filmed as a Minneapolis policeman pressed Floyd's neck and head to the ground with his knee. When shared on the internet it reverberated with similar incidents (like Eric Garner's death in police chokehold). It became an interfacial event collecting affective threads in relation to the structural racialized conditions of life and death. A break with historical colonial and continued oppression also grew from this event, most likely due to the clear-cut documentation and the interfacial intensifications of affect. The same is true for the growing public discontent with political leaders' lack of actions toward climate change as well as 
the global implications of \#MeToo that still lingers. In fact, in Denmark, at the time of writing we are witnessing a second wave of \#MeToo cases and media coverage due to the setting-up of whistleblower systems in many organizations.

These and other occurrences running parallel to the pandemic can be considered as an event of global dimensions, even though we do not yet know the full repercussions. The concurrency of this global event with Félix Guattari's three ecologies: a nascent subjectivity, a constantly mutating socius, an environment in the process of being reinvented (Guattari $1989 / 2000$ ) is articulated in this event of potential change. The bringing together of hitherto separated fields of experience, knowledge, and systems of control might suddenly be experienced affectively as an unfolding of the virtual, actualizing itself here and now and in a time to come. Thus, what we experience collectively and relationally - although differently - is that we are braced for "the immediacy of an affective event" that is modulating, questioning, displacing, and intensifying everything else (Massumi 2015, 115).

We cannot understand the cases of George Floyd, \#MeToo, or the current covid-19 pandemic without attending to the ways in which affects, interfaces, and events are entangled. Yet, all aspects of the entanglements of interfacial affective events are not spelled out in every chapter of the book.

The research project of Affects, Interfaces, Events is embedded in Scandinavia where access to internet, platforms, and technologies is vast, $98 \%$ of all Danes have access to internet at home and $96 \%$ of all households have mobile phones. Our experiences and perspectives are thus situated in the global North and shaped by our institutional, cultural, and personal backgrounds. We are acutely aware that we have only just begun this endeavor into the affective human and non-human conditions of what interfaces can do - and the joyful and the sad affects resulting from interfacial encounters. In this way, the chapters in the book are diverse prisms to un/fold a selection of contemporary conditions and act as a call for future explorations of interfacial entanglements and their evental affective imbrications. 


\section{THE RESEARCH GROUP}

The book presents an outcome of a five-year research collaboration within the framework of the Danish research project Affects, Interfaces, Events (2015-2021). The project was funded by the Independent Research Fund Denmark and directed by Professor Bodil Marie Stavning Thomsen (AU) with co-researchers Associate Professor Jette Kofoed (AU), Associate Professor Camilla Møhring Reestorff (AU), Associate Professor Kristine Samson (RUC), Associate Professor Jonas Fritsch (ITU), Associate Professor Thomas Markussen (SDU), Postdoc Torsten Andreasen (KU), and Dr. Søren Rasmussen (AU). The research groups' aim was identical with the aim of this publication, namely, to explore affective interface events through readings, writings, bodily experimentation, and design alternatives.

In the research period more people were invited to take part in the exploration of the affective encounters of interfaces. At workshops and in seminars, during the time span of the initial project, we exchanged ideas with Australian based Associate Professor Andrew Murphie (UNSW) and postdoc Lone Bertelsen (UNSW Art \& Design). Likewise, Professor Anna Munster (UNSW Art \& Design) participated in the group's workshop in 2018. All three have, in fruitful ways, taken part in the research and the design questions raised by members of the project, and all contribute chapters to this book. Professor Erin Manning (Concordia University) and Professor Brian Massumi who contribute via an interview by Jonas Fritsch, Greg Seigworth and Bodil Marie Stavning Thomsen, have inspired the framework of the research project (cf. Massumi 2002, 2011, 2015; Manning 2009). Some contributors have also been participating in the international project "Immediations: Art, Media and Event" (2013-2021), directed by Erin Manning.

Erin Manning, Brian Massumi, and Andrew Murphie were keynote speakers at the conference "Affects, Interfaces, Events" at Aarhus University in August 2018. Professor Gregory Seigworth (Millersville University), who has written the foreword, also contributed to the research group's work. He was a guest professor at the Department of Communication and Culture, AU in June 2019. In October 2019 he co-organized, with Andrew Murphie, Lone Bertelsen, and Jette Kofoed, a Nordic and North-European colloquium on Ethics and Affects in Aarhus. It has been a privilege to

exchange ideas with international colleagues across this evolving field and we are proud to include so many international contributions in this book. 


\section{SECTIONS AND CHAPTERS}

All authors included in this book were asked to reflect on the interface in relation to studies of affects and events pertaining to materials of their own choice. The editorial team invited some of the authors from the 2018 conference to extend their arguments and consider relations of the affective potentialities, qualities, and values of interfacial encounters and events. As a result of this editorial principle, the topics of the articles are very diverse. However, the focus on interfacial reinforcements or deteriorations of affective relations and events is the organizing principle of the book. The individual chapters are subsequently collated into four subsections according to their analytical approaches.

\section{Section One \\ ENCOUNTERING INTERFACES: INVESTIGATIONS IN HISTORY AND DESIGN}

The concept of 'interface' is discussed in the first section. The interface is explored in relation to affective interaction designs, to AI interfacial production of conversational assistants (and their limits), and to Pavlovian experiments with interfacing. All the chapters consider if and how interfacial encounters can place emphasis on, and reward, the complex potentials of relation.

Jonas Fritsch, in his chapter "Problematizing Affective Interaction Design," proposes two lines of mutual resonance between affect studies and interaction design. First, moving from design towards an affirmative ethics of technology in affect studies, and second moving from affect studies towards an ecological alter-politics of affect in design. He uses The Voice Pump, co-designed with digital artist Mogens Jacobsen, as a recurring design example to think through affect-political questions when designing for affective engagement and articulates the challenges that arise when doing so. Framing the chapter around problematization, in the end, turns into a call for further technological experimentation towards new re-fieldings of experience motivated by our troubled present.

Anna Munster's chapter "Disfluent Interfaces. Affective Conversations: Differencing Humans and Machines in AI," takes the interface conceived as "a space of engagement" across and between humans and computers as its point of departure. However, as Munster points out, 
interfaces have often been designed to avoid relation by either making computers imitate human behavior or by making humans enter computational designs. Her example is Google Duplex assistant which uses natural language processing (NLP) to perform tasks substituting human speech interaction. The complexity of human relationality in conversation is not achieved, but since Google Duplex used conversations among humans as its training field, the disfluency of language (like pauses and hesitations) was integrated. Meanwhile, the nonlinear, metastable and eventful developments in conversations could not be imitated, since conversations do not take place between predefined individual entities. This quality is, according to Munster, explored creatively in Monica Monin's artwork Conversation Theory (2019) that explores "sense-in-the making" rather than making sense.

Andrew Murphie's chapter "Technics Lifeless and Technics Alive: Activity without Content" argues that much of contemporary technics (here understood as all modes of organization and underpinnings of technology) fails to embrace the complexities of the world as event. On the contrary, the history of mainstream technics tends towards a "nature lifeless" controlling the relationality of affecting and being affected. Murphie argues that the current media revolution, involving AI and automation like VR and other powerful infoldings of media and world, too often takes up an ur-interface of "Pavlovism"; i.e. the production of near lifelessness. The procedures of isolation and constraint, in order to observe and measure and induce controlled behaviours, are seen as the building blocks for automation and interaction. However, this condition might be replaced by "an activity of concern," an "immanent relationality" and a wider "response-ability towards the world as medium." The ideas for "technics alive" are outlined in his closing manifesto.

\section{Section Two}

\section{WHAT DO INTERFACES DO? INESCAPABLE INTENSIFICATIONS}

The political and ethical approaches to events that produce and 'feed on' the affects raised in the manifold intensities of interfaces is one way of dealing with the specific entanglements of affects, interfaces, events. The chapters in this section deal with political and ethical refrains and reverberations arising from social media encounters by which actual bodies and social formations are controlled or framed. 
Jette Kofoed's chapter "Drawings in the Air: An Event of Digital Sexual Assault" investigates digital sexual assault as a matter of "spreading" where user generated content is circulated online. The chapter makes the non-consensual spreading of sexually-explicit videos the focus of analysis and scrutinizes how the spreading itself becomes an affective event of sexual assault. The so-called 'Umbrella case' makes up the empirical data. The chapter is composed of two entangled analyses, i.e., a diagrammatic reading of the pattern of the interfacial spreading over time and a reading of so-called $n-1$ dimensions. The author expands on how affect travels and returns in unforeseen ways, beyond the singularity of a seemingly demarcated 'case' and instead in ways that are deeply entangled with matters of ethics and methodology. Kofoed shows how the disparate spreadings are not only knotted together by interfacial technologies, but how the interfaces fashion the relationalities within what happens as part of the event.

Camilla Møhring Reestorff in "The Affective Politics of Interfacial News: Danish News Media's Coverage of \#MeToo on Facebook" explores how Danish news media covers the \#MeToo-movement on Facebook, and how news consumers respond to this coverage. In the chapter Reestorff discusses how the relationship between news and news consumers are transformed, and how the connections manifest in an affective politics of interfacial news. This affective politics of interfacial news is, she argues, impacted by both ordinary affects and a surveillance capitalist logic of accumulation; accumulations that among other things circulate and intensify angry refrains oriented at \#MeToo. Finally, Reestorff argues that the transformation of news cannot merely be explained by the affordances of social media and the impact of surveillance capitalism but must also take into account a specific politics concerning sexual harassment and abuse; a policy that foregrounds the emotionality of news consumers, intensifies angry refrains directed towards \#MeToo and has consequences for victims of sexual assault and harassment survivors' access to the public debate.

Kristian Møller and Chase Ledin's "Viral Hauntology: Specters of AIDS in Infrastructures of Gay Sexual Sociability" investigates how the increasingly effective biomedical treatments of the "post-AIDS crisis" have dethroned the condom as the ultimate safer-sex strategy. Despite these advances, the authors find that sociotechnical infrastructures recirculate sexual scripts rooted of previous medicalized realities. Two cases show how viral fears "haunt" the infrastructure of gay sexuality. First, they suggest that the figure of the "PrEP whore" is employed to shame 
those who use new chemoprophylactic methods, applying the norm of separated bodily fluids that decades of condom use has established to create a responsible subject. They then survey how popular hookup apps Grindr and Scruff support the negotiation of sexual health between users through infrastructrual disclosure options. Identifying the difference between disclosing practice and viral status, the authors argue that the latter reproduces fantasies of the HIV negative body that is rooted in the fear of the historical AIDS crisis.

\section{Section Three}

\section{WHAT COULD AN INTERFACE DO? THINKING-FEELING ART-RELATIONS}

Another approach is to pose questions as to how affect is or might be modulated within aesthetics and culture. Various art productions are brought in to explore new forms of relation. The qualification of events and questions of 'the new' are key to this section which places emphasis on affectability and the relational 'middle' of perception.

In Bodil Marie Stavning Thomsen's chapter "Interfacial Modulations of Affect: On the Creation of Events in Contemporary Artworks," Jesper Just's performance Cadavre Exquis (2019) is explored as an interfacial folding event. Thomsen underlines how the modulatory power of affective responses are key to the performance. The virtual folding capacity of perception as such is further explored as prehension in relation to Kirkegaard and Vindelev's performance EUSTACHIA - for Two Voices (2016). Here, the inner ear's sounds become the folding modulator of the heard encounters between the two singers. Even though the voices respond to unheard tonalities, the interfacial middling becomes almost palpable in the performance. In Lise Autogena and Joshua Portway's Foghorn Requium (2013), the modulating forces of the British coastal landscape were made audible, as the horns of the ships responded to the brass bands onshore. This composition along with the foghorn's last sounding event made the relation of coast and land affectively felt. This study of three art performances explores interfacial affect in terms of prehension and events.

Katrine Annesdatter-Madsen's chapter "Seeing Relation: The Perceptual Event in Olafur Eliasson's Art" explores Eliasson's use of natural sources like light, fog, water, and stone. Setting new scenes for encountering these materials shape the potentials for a non-representational and 
non-objectifying perception. Annesdatter-Madsen shows how Eliasson, in Beauty (1993) and Riverbed (2014), makes the gallery guests perceive the virtual relations lived in and through the artworks and thus makes way for an ecology of encounter.

In his chapter "Nonsense Data and The Anarchive: Memory in RealTime," Søren Rasmussen examines the process of making sense from the abundant streams of data that inform today's human-computer interactions. Rasmussen argues that real-time data processing has effectuated an anarchival amplification that breaks with traditional understandings of representation and time. Exemplified by the multimedia artworks The Pirate Cinema (2012) and Listening Post (2002), Rasmussen outlines the potentialities arising from the affective immediacy of the disorderly movements and temporalities of digital networks. In building theoretically upon Gilles Deleuze's concepts "the power of the false" and "peaks of present," Rasmussen argues that an engagement with the signaletic material of real-time procedures might revitalize virtual time and produce more than habitual responses to the increasingly indexed and accelerated interfacial encounters.

In their article "Atmospheric Intensities: Skin Conductance and the Collective Sensing Body" Liz de Freitas and David Rousell discuss the potentials of electro-dermal activity sensors (EDA) to map and explore the affective intensities of young people across the environment. Instead of a stimulus-response procedure covering individual intensities, EDA signals from multiple bodies were fed back into the environment. This enables an exploration of the "atmospheric intensity" and affective feed-back loops across bodies and events "without resorting to reductive models of quantification." Experiments with a group of young people's sensations of time in relation to William Kentridge's exhibition Thick Time is described in the chapter. This work's complex multi-sensory ecosystem composed the environment for the 'sense-mappings' of the creative vectors of the bodies in each exhibition room. The post-colonial intensities spelled out in sights, sounds, and movement in Kentridge's work formed transindividual resonances visible in the EDA sensors. Yet fielding into microtemporal modulations of affect, they argue, cannot change the invisible (unequal) conditions of bodies laid bare in the gallery rooms. 
Section Four

\section{FUTURE ENCOUNTERS: DRAFTING CO-CREATIVE DEMOCRACIES}

In this last section the question of interfacing is extended to also include the social field of distribution, regulation, confinement, and construction of class, gender, and race. The chapters focus on how wellknown forms of in- and exclusion work in the current interface culture and its ideologic undercurrents.

In Kristine Samson's chapter "We Still Do Not Know What a City Can Do: Modulation of Affect in Urbanism and Spatial Politics" the key issue is to explore cities and city planning as interfaces in which bodies are diagrammed as related, distributed, or included/excluded. Samson argues that cities are technologically mediated by the media of their time and thus she focuses on how the current interface culture redistributes "urban encounters on macro-, meso-, and microscales." She discusses actual modulations of control in monitoring engagement and participation in city planning, and she takes a closer look on the 'interfacial modulation of affective relations between buildings, people, aesthetics and culture." The norms of participation under the label of Nordic transparency are exposed in The Demolition Tour, an art project by Gellerup resident Aysha Amin. The project makes the tour guests experience the diagram of how the municipality of Aarhus wants to refashion and give another 'face' to Amin's childhood area as a response to the Danish Ghetto Law of 2018. This example of making other events and minor gestures between citizens deviate from planned modulations can also be extended to cover potential non-human encounters outside the city-scape due to the covid-19 pandemic.

In "Interfaces for Ecosophic Democracies: 'Consent not to be a Single Being," " Lone Bertelsen approaches interfacial events by way of a speculation on what it would take to create real social collectivities. Systemic oppression is maintained through the production of a self-enclosed subjectivity, which distances itself from the very ability to be affected. This is key to the production of racism, profit, and (neo)liberal exploitation. When the ideas of sovereign subjects are reproduced in interface development, real democratic practices cannot exist. Bertelsen explores alternative practices emerging from the artworks Crystal Palace: The Great 
Exhibition of the Works of Industry of all Nuclear Nations (2013) and Collective Fabulations: Propositions for Social Dreaming (2019). Engagement with these participatory works involves co-affective becoming.

In the interview "Infrafacing" Erin Manning and Brian Massumi respond to questions around the concept of interfacing as posed by Bodil Marie Stavning Thomsen, Jonas Fritsch, and Gregory Seigworth. Manning and Massumi focus first on the transversality made available in the new implications for writing and reading in the context of the design of their online journal Inflexions. Here, the multiple rhythms of moving eyes and hands are explored as an "infraface" to enhance the transversal modalities of events. The infraface can be thought of as a threshold that allows attunement to the immediacy of relation and, thus, can invite other forms of collaboration. Becoming aware of racialized, disabled, neurodiverse responses in navigating (entering and exiting) might invite a variety of opportunities for participation. By taking into account the systemic operation of the white man's face as the operator of legibility (by territorializing other bodies and the ecologies of the earth), the question becomes how to dismantle the 'face' of the interface for the horizons of the infraface. The demands of affective interaction would thus be to work with co-becoming, qualitative transformation, and reciprocal modulation of relation.

\section{REFERENCES}

Deleuze, G. (1988). Spinoza: Practical Philosophy. San Francisco: City Lights Books.

Deleuze, G. (1989). Cinema 2: The Time-Image. Minneapolis: University of Minnesota Press.

Gregg, M. \& Seigworth, G.J. (2010). The Affect Theory Reader. Durham: Duke University Press.

Guattari, F. (1989/2014). The Three Ecologies. London: Bloomsbury. Manning, E. (2009). Relationscapes: Movement, Art Philosophy. Cambridge \& London: MIT Press.

Manning, E., Munster, A. \& Thomsen, B. M. S. (2019). Immediation I \& II. London: Open Humanities Press.

Massumi, B. (2002). Parables for the Virtual: Movement, Affect, Sensation. Durham: Duke University Press. 
Massumi, B. (2011). Semblance and Event: Activist Philosophy and the Occurrent Arts. Cambridge \& London: MIT Press.

Massumi, B. (2015). Politics of Affect. Cambridge: Polity Press.

Munster, A. (2006). Materializing New Media: Embodiment in Information Aesthetics. Dartmouth: Dartmouth College Press.

Spinoza, B. (1677; 2010): Ethics. Hertfordshire: Worthworth Editions Limited.

Thomsen, B. M. S. (2012). Signaletic, Haptic and Real Time Material.Journal of Aesthetics and Culture [online], 4 (1). Available at: https://www. tandfonline.com/doi/full/10.3402/jac.v4io.18148 [Accessed 01 January 2021]. 